\title{
Antibiotic resistance among verocytotoxigenic Escherichia coli (VTEC) and non-VTEC isolated from domestic animals and humans
}

\begin{abstract}
Correspondence
Karl A. Bettelheim

k.bettelheim@microbiology.uni

melb.edu.au
\end{abstract}

Received 15 February 2002

Accepted 7 October 2002

\author{
Karl A. Bettelheim, ${ }^{1}$ Michael A. Hornitzky, ${ }^{2}$ Steven P. Djordjevic ${ }^{2}$ and \\ Alexander Kuzevski ${ }^{1}$
}
${ }^{1}$ Microbiological Diagnostic Unit, Public Health Laboratory, Department of Microbiology and Immunology, University of Melbourne, Royal Parade, Parkville, Victoria, Australia 3052
${ }^{2}$ Elizabeth Macarthur Agricultural Institute, Private Mail Bag 8, Camden, New South Wales, Australia 2570

\begin{abstract}
Two hundred verocytotoxigenic and 216 non-verocytotoxigenic Escherichia coli (VTEC and non-VTEC), isolated from a variety of sources were tested for their resistances to 11 antimicrobial agents. The strains included isolates from domestic food animals and both symptomatic and asymptomatic infections in man. A much higher level of resistance was found among the non-VTEC than among the VTEC, regardless of source. The resistant VTEC isolated from animals were predominantly from specimens associated with sick animals. Antibiotic resistance was detected in only four of the $59(6.8 \%)$ VTEC of human origin, whereas more of the human non-VTEC possessed antibiotic resistance determinants. It was particularly noteworthy that $24 / 87$ (28\%) strains isolated from healthy babies, who had neither contact with antibiotics nor had gastrointestinal symptoms for at least 2 weeks prior to the specimen being taken, were resistant to one or more of the antibiotics tested.
\end{abstract}

\section{INTRODUCTION}

Extensive studies over the years, both by ourselves and others around the world, have shown that verocytotoxigenic Escherichia coli (VTEC) are commonly isolated from the faeces of ruminants such as cattle and sheep (Beutin et al., 1993; Djordjevic et al., 2001; Dorn et al., 1989; Fagan et al., 1999; Hornitzky et al., 2001; Kudva et al., 1997; Richter et al., 1997; Wells et al., 1991). In addition, there has been increasing concern of the possible development of resistance to antimicrobial agents in the Enterobacteriaceae, especially $E$. coli, as a result of the use of such agents in animal feed (Willis, 2000). With the recent emergence of strains of Salmonella Typhimurium DT104, resistant to four or more antimicrobial agents (Threlfall et al., 1997), the problem of such resistant organisms evolving and being transmitted through the food chain from cattle and sheep to man is becoming increasingly important throughout the world (Glynn et al., 1998; Levy \& Cruz, 1999). In his review, Willis (2000) concludes that 'there is now good evidence that the use of antibiotics in agriculture is contributing to the problem of antibiotic resistance amongst pathogenic bacteria.'

Abbreviations: HC, haemorrhagic colitis; HUS, haemolytic uraemic syndrome; UTI, urinary tract infection; VT, verocytotoxigenic; VTEC, verocytotoxigenic Escherichia coli.
In her book, Garrett (1995) discusses the problems associated with the acquisition of antibiotic resistance factors by the intestinal organisms of domestic animals, as a result of the use of antibiotics in animal husbandry. She then discusses the emergence of VTEC, especially E. coli O157 : H7, and suggests that these may well also have emerged due to such antibiotic use. It seemed that if this hypothesis were true then VTEC isolated from cattle and sheep would be resistant to antibiotics. It was specifically to address this question that this study was initiated, especially as there are few studies in which the antibiotic sensitivities of VTEC have been determined. Most of these deal with human VTEC. Zhao et al. (2001) demonstrated that 39/50 (78\%) VTEC, mainly O157: H7, but also including a range of serotypes, exhibited resistance to two or more antimicrobial classes. Most of these were isolated from cattle or ground beef. Only eight of the strains were isolated from man. Multiple resistances to streptomycin, sulfamethoxazole and tetracycline were most often observed. Stephan \& Kuhn (1999) identified VTEC in $4 / 145(2 \cdot 8 \%)$ E. coli isolates from cows with mastitis. One isolate showed multiple antibiotic resistances to ampicillin, neomycin, tetracycline and sulphonamide. Earlier studies in Spain (Gonzales \& Blanco, 1989) of VTEC and non-VTEC isolated from calves with diarrhoea showed that the majority ( $81 \%)$ of VTEC were resistant to at least one of six antimicrobial agents tested with $41 \%$ being resistant to five 
antimicrobial agents. There appear to have been no studies reported on antimicrobial sensitivities of ovine VTEC.

The paucity of data on the resistance of VTEC to antibiotics prompted us to determine the extent to which VTEC isolated from domestic animals, especially cattle and sheep, and man were resistant to a range of antibiotics. These resistance patterns were then compared to those produced by nonVTEC isolated from the same species.

\section{METHODS}

Strains of E. coli. The 416 E. coli strains used in this study were all from the culture collection of the National Escherichia coli Reference Laboratory, Microbiological Diagnostic Unit, Public Health Laboratory, Department of Microbiology and Immunology, University of Melbourne, Australia. The selection was largely based on availability, and in attempting to obtain a reasonable basis for the comparison between VTEC and non-VTEC, to also test as great a variety of sources and serotypes as possible.

Most of the 109 bovine and 53 ovine strains were from earlier studies (Fagan et al., 1999; Djordjevic et al., 2001; Hornitzky et al., 2001). They also included seven bovine strains from Hong Kong (Leung et al., 2001). The bovine strains included 16 strains isolated from the faeces of healthy pre-slaughter pasture beef cattle, 38 from healthy pre-slaughter feedlot cattle and 23 from faecal samples submitted from cattle for diagnostic purposes. Also included were 20 isolates from the rumens of healthy cattle and five beef isolates. Of the 53 ovine strains, 13 were from preslaughter adult sheep, 37 from pre-slaughter lambs and three from ovine diagnostic samples. Of the 47 porcine strains, 27 were from samples submitted from pigs for diagnostic purposes and 20 were from healthy pigs. All these animal strains had been isolated in the years 1996-2001 except the diagnostic porcine samples, some of which had been isolated in the 1970s and the remainder in the 1990s.

The 207 human strains were all collected as part of the work of the laboratory (Bettelheim, 2001). The 87 strains from healthy babies had been collected between 1989 and 1992 from healthy infants under 1 year of age who had not had gastrointestinal symptoms or been treated with antibiotics for any reason for at least 2 weeks prior to obtaining the specimen. Apart from age and gender, these were the only data we were ethically permitted to take. Of the remaining 120 strains, which had all been isolated during the last 6 years, 12 were from healthy adults, 29 were isolated from cases of diarrhoea, 13 were from cases of haemorrhagic colitis (HC), 33 were from cases of haemolytic uraemic syndrome (HUS), one from a case of human septicaemia and 10 from urinary tract infections (UTIs). For 22 human isolates, the symptoms were not adequately given.

The bovine non-VTEC were obtained from Dr C. S. McSweeney, CSIRO, Longpocket, Brisbane, Australia. Apart from the seven bovine strains from Hong Kong, all other strains were isolated in Australia.

Characterization of E. coli. The strains were characterized as E. coli on the basis of their reactions in triple-sugar-iron (TSI) agar (Oxoid), motility-indole-ornithine (MIO) medium (Oxoid), ONPG (Oxoid) and urease broth (Oxoid). Strains were considered to be E. coli if the results obtained with these tests conformed to the description of the species. Those producing aberrant results were subjected to additional tests. The E. coli were then $\mathrm{O}$ and $\mathrm{H}$ serotyped (Bettelheim \& Thompson, 1987; Chandler \& Bettelheim, 1974). Supernate preparations were tested on Vero cells (Konowalchuk et al., 1977) and also tested by ELISA using mAbs 13C4 and 11E10 directed against VT1 and VT2, respectively (Acheson et al., 1990).
Antimicrobial testing. The E. coli isolates were tested for their sensitivity to a range of antimicrobials by the plate/replicator method. The antimicrobials used were ampicillin $\left(32 \mathrm{mg} \mathrm{ml}^{-1}\right)$, streptomycin (25 $\left.\mathrm{mg} \mathrm{l}^{-1}\right)$, tetracycline $\left(20 \mathrm{mg} \mathrm{l}^{-1}\right)$, chloramphenicol $\left(10 \mathrm{mg} \mathrm{l}^{-1}\right)$, sulphathiazole (550 $\left.\mathrm{mg} \mathrm{l}^{-1}\right)$, trimethoprim $\left(50 \mathrm{mg} \mathrm{l}^{-1}\right)$, kanamycin $\left(10 \mathrm{mg} \mathrm{l}^{-1}\right)$, nalidixic acid $\left(50 \mathrm{mg}^{-1}\right)$, spectinomycin $\left(50 \mathrm{mg} \mathrm{l}^{-1}\right)$, gentamicin $\left(2 \cdot 5 \mathrm{mg} \mathrm{l}^{-1}\right)$ and ciprofloxacin $\left(2 \mathrm{mg} \mathrm{l}^{-1}\right)$. The results obtained were treated as epidemiological markers and the $E$. coli were recorded as resistant to an antimicrobial rather than sensitive to the antimicrobial. The antimicrobials were incorporated in lysed blood isosensitest agar (Oxoid). Plates and cultures were tested by a method similar to that used for MIC using a Clements antibiotic sensitivity replicator with 32 prongs.

To perform the test, the E. coli and controls were grown up in double strength nutrient broth (Oxoid) in an orbital shaker at 100 r.p.m. for 1.5 $\mathrm{h}$, at $37^{\circ} \mathrm{C}$. The organisms were then diluted $1: 10(\mathrm{v} / \mathrm{v})$ in tryptone water (Oxoid) and added to the wells of the antibiotic sensitivity replicator, which were filled with $0.5 \mathrm{ml}$ nutrient broth containing $0.05 \%$ agar. The E. coli were inoculated, by means of the replicator, onto each of the antimicrobial agar plates and then incubated at $37^{\circ} \mathrm{C}$ overnight. The plates were examined the following day and no (or very little) growth of the E. coli on the plate was recorded as demonstrating sensitivity to that specific antimicrobial. This method had originally been developed to determine the resistance patterns of Salmonella isolates, therefore, two standard strains, Salmonella Heidelberg and Salmonella Hadar with known resistances were used as positive controls and a fully sensitive strain of Salmonella Typhimurium was used as negative control. All strains were tested against all the antimicrobials listed above; however, only the strains for which antibiotic resistances were observed are listed in Tables 2 and 3.

\section{RESULTS}

\section{Relationship of antibiotic resistance to verotoxigenicity of $E$. coli}

Of the 416 E. coli used in this study, $200(48 \cdot 1 \%)$ were VTEC and $216(51.9 \%)$ were non-VTEC. Thirty-one of 200 $(15.5 \%)$ of the VTEC and 70/216 (32.9\%) of the non-VTEC were resistant to at least one antibiotic (Table 1). Of the VTEC isolates, which showed antibiotic resistance, 5/31 $(16 \cdot 1 \%)$ were of bovine origin and these were all isolated from diagnostic samples. None was identified in sheep. Seventy-one percent $(22 / 31)$ of porcine origin were resistant and consisted of $7 / 11(63.6 \%)$ from healthy pigs and 15/20 ( $75.0 \%)$ from porcine diagnostic samples. Four of $59(6.8 \%)$ resistant VTEC were of human origin. Similar ranges of resistance patterns were observed with the porcine isolates from the 1970s and 1990s.

Of the non-VTEC, $71 / 216(32.9 \%)$ showed antibiotic resistance. Two of $26(7.7 \%)$ were of bovine origin, 1/26 $(3.8 \%)$ was of ovine origin and $14 / 16(87.5 \%)$ were from pigs (eight healthy and six porcine diagnostic samples). Of the human isolates 54/148 (36.5 \%) showed resistance (Table 1).

\section{Resistance patterns of VTEC}

Tetracycline (either alone or combined with other antibiotic resistances) was the most common antibiotic against which VTEC showed resistance $(17 / 31 ; 54 \cdot 8 \%)$ and was found in isolates from human infection (2), sick pigs (8), healthy pigs 
Table 1. Relationship of antibiotic resistances to verocytotoxigenicity of $E$. coli isolates

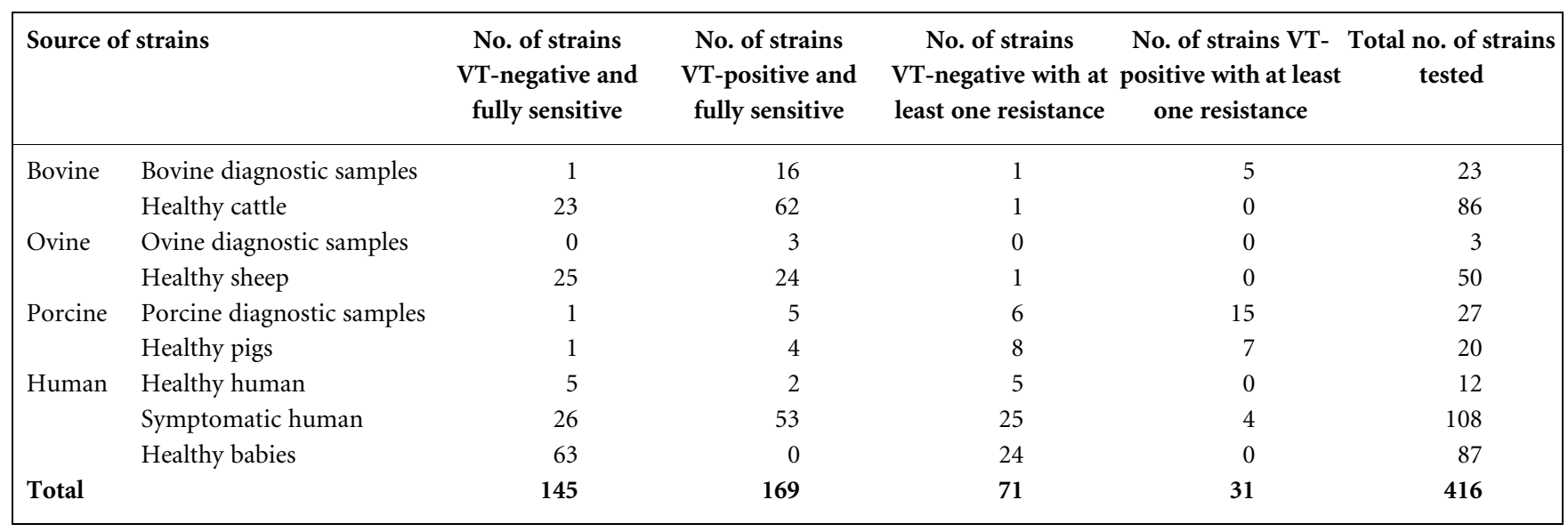

(6) and a bovine diagnostic isolate. Resistance to both streptomycin and sulphathiazole was noted in $15 / 31$ $(48 \cdot 4 \%)$ and was the second most frequently found resistance pattern, often in combination with other resistances. This resistance was found in VTEC from bovine diagnostic samples (4), human infections (3) and sick pigs (8). Chloramphenicol resistance was only detected in VTEC from porcine diagnostic samples (Table 2).

\section{Resistance patterns of non-VTEC}

Antibiotic resistance was more commonly found in nonVTEC isolates from sick animals and man. Non-VTEC were most commonly resistant to sulphathiazole $(44 / 216 ; 20.4 \%)$, ampicillin (40/216; 18.5\%) and tetracycline (34/216; $15 \cdot 7 \%)$. Resistances to nalidixic acid and ciprofloxacin were the least prevalent, being found in one strain from a human UTI case, which also had six other resistances.

\section{DISCUSSION}

The main aim of this study was to ascertain to what extent VTEC isolated from cattle and sheep, which may enter the food chain, are resistant to antibiotics. While it is currently not considered appropriate to treat VTEC infections, such as HUS with antibiotics (Wong et al., 2000; Zimmerhackl, 2000), there are significant disadvantages for VTEC infections to be caused by multiple resistant strains. In the presence of antibiotics such strains may have a selective advantage and therefore be more likely to cause an outbreak.

Of the 109 bovine E. coli isolates studied, of which 84 were VTEC, antibiotic resistance was detected in only five of these strains (Table 1). These five strains were all isolated from sick animals with gastrointestinal conditions. It is further noteworthy, that three of these strains belonged to serotypes $\mathrm{O} 5: \mathrm{H}$ - and $\mathrm{O} 111$ : H8 (Table 2), which are rarely encountered among healthy cattle in Australia (M. A. Hornitizky and others, unpublished). However, VTEC with serotype $\mathrm{O} 5: \mathrm{H}$ - have been more frequently recovered from faeces from cattle with diarrhoea in Germany (Wieler et al., 1996). VTEC of serotype O5:H- have been commonly isolated from healthy sheep (Djordjevic et al., 2001; Ramachandran et al., 2001). Strains belonging to the third VTEC serotype, O26:H11, have been commonly isolated from cattle (Hornitzky et al., 2001) and rarely from healthy sheep (Djordjevic et al., 2001; Ramachandran et al., 2001). These three VTEC serotypes have been associated with human disease around the world. Interestingly, none of the $38 \mathrm{E}$. coli isolates, of which 36 were VTEC, recovered from feedlot cattle displayed antibiotic resistance. Of the two bovine nonVTEC resistant to antibiotics, one was also isolated from a bovine diagnostic sample and the second was isolated from a beef specimen (Table 3 ). The former belonged to a serotype not reported in the literature as associated with human disease and the latter to an O-untypable group; therefore, no further conclusions can be drawn.

These results suggest that bovine E. coli from healthy Australian cattle do not present a high risk of spreading antibiotic-resistant $E$. coli to man. Our data are in contrast to high levels (78 and 49\%) of antibiotic-resistant VTEC recently reported by Zhao et al. (2001) and Khan et al. (2002). However, given the high rates of antibiotic-resistant VTEC from diarrhoeagenic calves reported in Spanish studies (Gonzales \& Blanco, 1989), further studies of E. coli isolates from cattle with gastrointestinal diseases are needed to determine if such isolates pose the greatest risk of developing multiple antibiotic resistances. These conclusions are even more appropriate when examining the antibiotic sensitivity of 53 ovine isolates in this study (Table 1). All but one strain, a non-VTEC, were fully sensitive to all antibiotics used. This strain from a healthy adult sheep (Table 3) belonged to serotype O117:H21, which has not been associated with human disease.

Compared with cattle and sheep, there were a greater number of antibiotic-resistant VTEC as well as non-VTEC isolated from pigs (Tables 2 and 3). However, the majority (21/27; $77 \cdot 8 \%$ ) were isolated from sick animals. Fourteen of 27 
Table 2. Antibiotic resistance patterns of VTEC isolates

Abbreviations: A, ampicillin; S, streptomycin; T, tetracycline; C, chloramphenicol; Su, sulphathiozole; Tm, trimethoprim; K, kanamycin; Sp, spectinomycin. Symbols: + , resistant; - , sensitive.

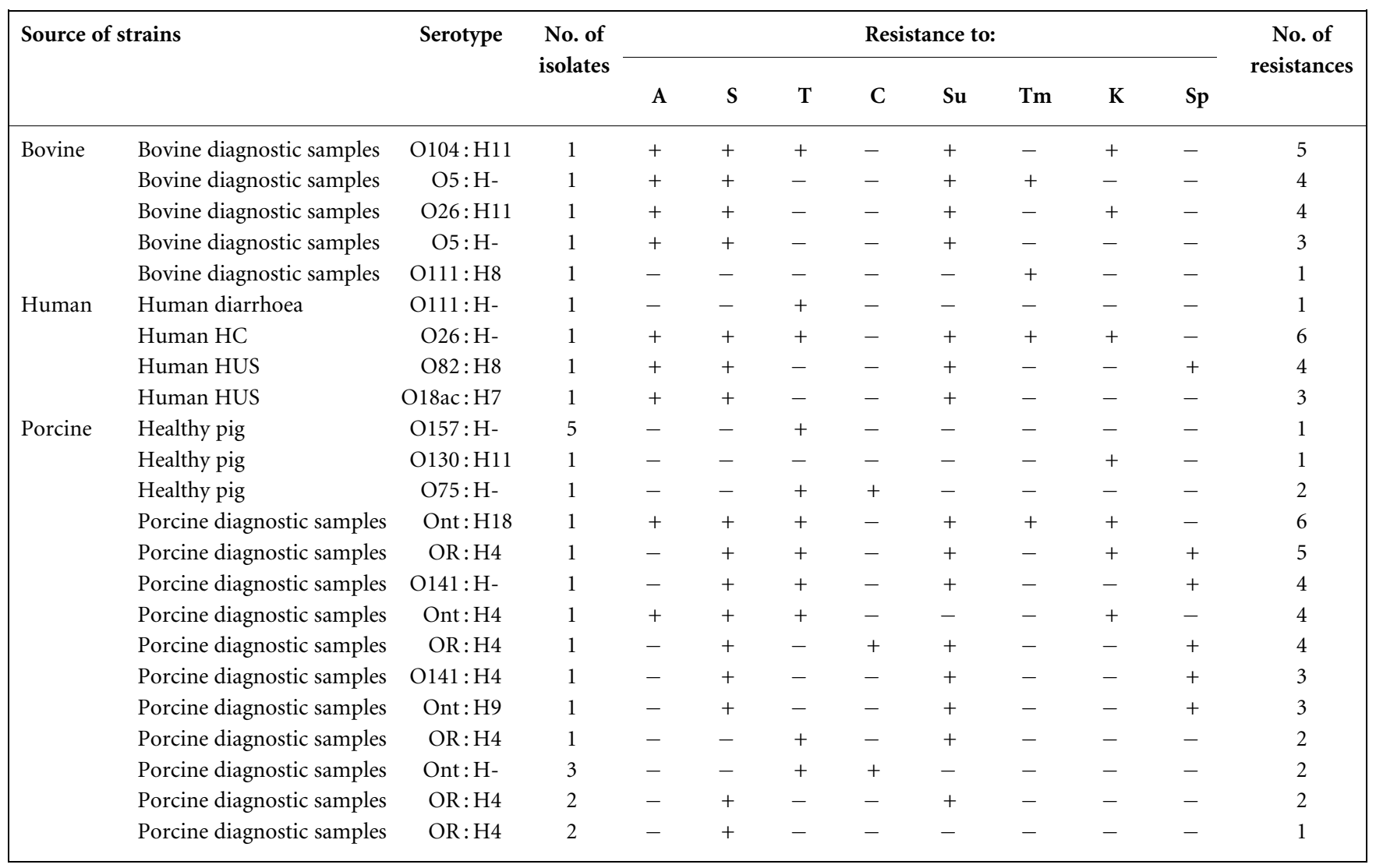

$(51.9 \%)$ of these were resistant to tetracycline, an antibiotic commonly used in the Australian pig industry either as a growth promotant or for the control of enteric and respiratory diseases (Johnston, 1987). Thirteen of these 27 (48.1\%) porcine $E$. coli isolates were resistant to kanamycin. Neomycin, a structurally closely related molecule, has been routinely used as a broad-spectrum antimicrobial for the treatment of enteritis in the Australian pig industry (Johnston, 1987). Certain VTEC are accepted porcine pathogens and it is therefore not surprising to find resistant strains presumably as a result of veterinary therapy. Only seven VTEC isolates, three of which were resistant to one or more antibiotics, were recovered from healthy swine in this study. Further studies are required to establish the level of antibiotic resistance among $E$. coli derived from healthy swine. A recent study (Schroeder et al., 2002) on E. coli O157 isolates from humans, cattle, swine and food showed a similar tendency with the highest number of resistant strains being of porcine origin, with those of human and bovine origin having a low number of resistance determinates. This contrasts with results reported among VTEC recovered from human infections in England and Wales between 1995 and 1998 where approximately $20 \%$ of these strains were resistant to at least one antimicrobial agent (Willshaw et al., 2001). It is likely that the health status of meat-producing animals prior to slaughter, animal husbandry and herd management practices are likely to impinge significantly on the ability of antibiotic-resistant bacteria to make their way into the human food chain.

The adult human isolates which were studied in parallel included strains isolated from cases of UTI, where antibiotic treatment is the rule (Sotto et al., 2001) as well as strains from cases of HUS, where it is not. Only four VTEC out of the 59 human VTEC isolated were found with antibiotic resistance (Table 1). These included two serotypes, O26:H- and O111: H-, which are commonly isolated from human VTEC infections around the world and interestingly were also shown to be resistant when isolated from cattle in this study. The other two antibiotic-resistant VTEC were found to belong to rarer serotypes O82:H8 and O18ac: H7.

A much higher percentage of resistant human E. coli (36.5\%; $54 / 148)$ isolates compared to animal isolates ( $25 \%$; 17/68) was noted among the non-VTEC (Table 3). Many of these antibiotic-resistant human isolates belonged to serotypes commonly associated with human infections such as UTI (Bettelheim, 1997) and enteropathogenic E. coli. Nonetheless, many of these isolates demonstrated multiple resistances to antibiotics. Of interest was the observation that $37 / 54$ $(66 \%)$ resistant isolates were resistant to ampicillin, an antibiotic where resistance was poorly recorded among 
Table 3. Antibiotic resistance patterns of non-VTEC isolates

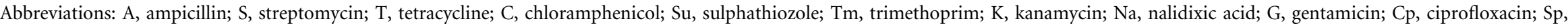
spectinomycin. Symbols: +, resistant; -, sensitive.

\begin{tabular}{|c|c|c|c|c|c|c|c|c|c|c|c|c|c|c|c|}
\hline \multicolumn{2}{|c|}{ Source of strains } & \multirow[t]{2}{*}{ Serotype } & \multirow{2}{*}{$\begin{array}{l}\text { No. of } \\
\text { isolates }\end{array}$} & \multicolumn{11}{|c|}{ Resistance to: } & \multirow{2}{*}{$\begin{array}{c}\text { No. of } \\
\text { resistances }\end{array}$} \\
\hline & & & & $\mathbf{A}$ & $S$ & $\mathbf{T}$ & $\mathrm{C}$ & Su & $\mathrm{Tm}$ & $\mathbf{K}$ & $\mathrm{Na}$ & G & $\mathrm{Cp}$ & Sp & \\
\hline \multirow[t]{2}{*}{ Bovine } & Bovine diagnostic sample & $\mathrm{O} 21: \mathrm{H} 21$ & 1 & - & - & + & - & - & - & - & - & - & - & - & 1 \\
\hline & Bovine meat & Ont: $\mathrm{H} 21$ & 1 & - & + & + & + & + & - & - & - & - & - & + & 5 \\
\hline Ovine & Healthy sheep & $\mathrm{O} 117: \mathrm{H} 21$ & 1 & - & + & + & - & + & - & - & - & - & - & - & 3 \\
\hline \multirow[t]{11}{*}{ Porcine } & Healthy pig & Ont:H11 & 4 & - & + & + & - & + & - & + & - & - & - & + & 5 \\
\hline & Healthy pig & Ont: H11 & 1 & - & - & + & - & + & - & + & - & - & - & + & 4 \\
\hline & Healthy pig & O157: H32 & 1 & + & - & + & + & - & - & - & - & - & - & - & 3 \\
\hline & Healthy pig & O126:H11 & 1 & - & + & + & - & + & - & - & - & - & - & - & 3 \\
\hline & Healthy pig & $\mathrm{O} 75: \mathrm{H}-$ & 1 & - & - & + & + & - & - & - & - & - & - & - & 2 \\
\hline & Porcine diagnostic samples & O157:H- & 1 & - & + & + & - & + & + & + & - & + & - & - & 7 \\
\hline & Porcine diagnostic samples & O149:H- & 1 & - & - & + & + & + & + & + & - & - & - & + & 6 \\
\hline & Porcine diagnostic samples & $\mathrm{O} 21: \mathrm{H}-$ & 1 & + & + & + & - & - & - & + & - & - & - & + & 5 \\
\hline & Porcine diagnostic samples & O157:H19 & 1 & - & + & + & - & + & - & - & - & - & - & + & 4 \\
\hline & Porcine diagnostic samples & O157: H32 & 1 & + & - & + & + & - & - & - & - & - & - & - & 3 \\
\hline & Porcine diagnostic samples & $\mathrm{O} 20: \mathrm{H}-$ & 1 & - & - & + & - & - & - & + & - & - & - & - & 2 \\
\hline \multirow[t]{20}{*}{ Human } & Human symptoms unknown & $\mathrm{O} 111: \mathrm{H} 2$ & 1 & + & + & - & - & + & + & + & - & + & - & - & 6 \\
\hline & Human symptoms unknown & O6: Hnt & 1 & + & + & + & - & + & + & - & - & - & - & - & 5 \\
\hline & Human symptoms unknown & $\mathrm{O} 111: \mathrm{H} 4$ & 1 & + & + & + & - & + & + & - & - & - & - & - & 5 \\
\hline & Human symptoms unknown & O5 : H4 & 1 & - & - & + & - & + & - & - & - & - & - & - & 2 \\
\hline & Human symptoms unknown & $\mathrm{O} 55: \mathrm{H}-$ & 1 & - & + & - & - & + & - & - & - & - & - & - & 2 \\
\hline & Human symptoms unknown & $\mathrm{O} 4: \mathrm{H}-$ & 1 & + & - & - & - & - & - & - & - & - & - & - & 1 \\
\hline & Human symptoms unknown & O157:H- & 1 & + & - & - & - & - & - & - & - & - & - & - & 1 \\
\hline & Human diarrhoea & $\mathrm{O} 111: \mathrm{H} 2$ & 1 & + & + & - & - & - & + & - & - & + & - & - & 4 \\
\hline & Human diarrhoea & $\mathrm{O} 111: \mathrm{H} 4$ & 1 & - & + & + & - & - & - & - & - & - & - & - & 2 \\
\hline & Human diarrhoea & $\mathrm{O} 123: \mathrm{H}-$ & 1 & - & - & + & - & + & - & - & - & - & - & - & 2 \\
\hline & Human diarrhoea & $\mathrm{O} 111: \mathrm{H} 8$ & 1 & - & - & + & - & - & - & - & - & - & - & - & 1 \\
\hline & Human diarrhoea & O111:H- & 1 & - & - & + & - & - & - & - & - & - & - & - & 1 \\
\hline & Human HC & O55 : H5 & 1 & + & + & + & + & + & + & - & - & - & - & - & 6 \\
\hline & Human HUS & O6:H- & 1 & + & + & - & - & + & - & - & - & - & - & - & 3 \\
\hline & Human HUS & $\mathrm{O} 6: \mathrm{H} 1$ & 1 & + & - & - & - & + & - & - & - & - & - & + & 3 \\
\hline & Human HUS & $\mathrm{O} 11: \mathrm{H}-$ & 1 & - & - & - & - & - & + & - & - & - & - & - & 1 \\
\hline & Human HUS & O86 : H18 & 1 & + & - & - & - & + & - & - & - & - & - & - & 2 \\
\hline & Human UTI & $\mathrm{O} 2: \mathrm{H}-$ & 1 & - & - & - & - & - & + & - & - & - & - & - & 1 \\
\hline & Human UTI & O6: H1 & 1 & + & + & - & - & + & - & - & - & - & - & + & 4 \\
\hline & Human UTI & $\mathrm{O} 6: \mathrm{H} 1$ & 1 & + & - & + & - & - & + & - & - & - & - & - & 3 \\
\hline
\end{tabular}


Table 3. cont.

\begin{tabular}{|c|c|c|c|c|c|c|c|c|c|c|c|c|c|c|}
\hline \multirow[t]{2}{*}{ Source of strains } & \multirow[t]{2}{*}{ Serotype } & \multirow{2}{*}{$\begin{array}{l}\text { No. of } \\
\text { isolates }\end{array}$} & \multicolumn{11}{|c|}{ Resistance to: } & \multirow{2}{*}{$\begin{array}{c}\text { No. of } \\
\text { resistances }\end{array}$} \\
\hline & & & A & $S$ & $\mathrm{~T}$ & C & $\mathrm{Su}$ & $\mathrm{Tm}$ & $\mathbf{K}$ & $\mathrm{Na}$ & G & $\mathrm{Cp}$ & Sp & \\
\hline Human UTI & $\mathrm{O} 6: \mathrm{H} 1$ & 1 & - & + & - & - & + & + & - & - & - & - & - & 3 \\
\hline Human UTI & $\mathrm{O} 6: \mathrm{H} 1$ & 1 & + & - & - & - & + & - & - & - & - & - & + & 3 \\
\hline Human UTI & $\mathrm{O} 20: \mathrm{H}-$ & 1 & - & - & + & - & + & + & - & - & - & - & - & 3 \\
\hline Human UTI & $\mathrm{O} 25: \mathrm{H}-$ & 1 & + & - & + & - & + & + & - & - & - & - & - & 4 \\
\hline Human UTI & $\mathrm{O} 172: \mathrm{H} 23$ & 1 & + & - & + & + & - & + & + & + & + & + & - & 8 \\
\hline Human healthy baby & $\mathrm{O} 4: \mathrm{H} 1$ & 1 & + & - & + & - & + & + & - & - & - & - & - & 4 \\
\hline Human healthy baby & OR:H2 & 1 & + & + & - & - & + & - & - & - & - & - & - & 3 \\
\hline Human healthy baby & Ont: H- & 1 & + & + & - & - & + & - & - & - & - & - & - & 3 \\
\hline Human healthy baby & O6 : H31 & 1 & + & - & + & - & + & - & - & - & - & - & - & 3 \\
\hline Human healthy baby & $\mathrm{O} 25: \mathrm{H} 4$ & 1 & + & - & + & - & + & - & - & - & - & - & - & 3 \\
\hline Human healthy baby & O6:H1 & 1 & - & + & - & - & + & + & - & - & - & - & - & 3 \\
\hline Human healthy baby & $\mathrm{OR}: \mathrm{H} 4$ & 1 & - & + & - & - & + & - & - & - & - & - & + & 3 \\
\hline Human healthy baby & $\mathrm{O} 1: \mathrm{H} 7$ & 1 & + & - & + & - & - & - & - & - & - & - & - & 2 \\
\hline Human healthy baby & $\mathrm{O} 2: \mathrm{H} 1$ & 1 & + & - & - & - & + & - & - & - & - & - & - & 2 \\
\hline Human healthy baby & $\mathrm{O} 2: \mathrm{H} 4$ & 1 & + & - & + & - & - & - & - & - & - & - & - & 2 \\
\hline Human healthy baby & $\mathrm{O} 4: \mathrm{H} 5$ & 1 & + & - & - & - & + & - & - & - & - & - & - & 2 \\
\hline Human healthy baby & $\mathrm{O} 6: \mathrm{H}-$ & 2 & + & - & - & - & + & - & - & - & - & - & - & 2 \\
\hline Human healthy baby & $\mathrm{O} 21: \mathrm{H}-$ & 1 & + & - & - & - & - & + & - & - & - & - & - & 2 \\
\hline Human healthy baby & $\mathrm{O} 25: \mathrm{H} 1$ & 2 & + & - & - & - & + & - & - & - & - & - & - & 2 \\
\hline Human healthy baby & Ont: $\mathrm{H} 1$ & 1 & + & - & - & - & + & - & - & - & - & - & - & 2 \\
\hline Human healthy baby & Ont: H1 & 1 & - & + & - & - & + & - & - & - & - & - & - & 2 \\
\hline Human healthy baby & OR: H34 & 1 & + & - & + & - & - & - & - & - & - & - & - & 2 \\
\hline Human healthy baby & O7 : H15 & 1 & + & - & - & - & - & - & - & - & - & - & - & 1 \\
\hline Human healthy baby & $\mathrm{O} 11: \mathrm{H}-$ & 1 & + & - & - & - & - & - & - & - & - & - & - & 1 \\
\hline Human healthy baby & O62: H48 & 1 & + & - & - & - & - & - & - & - & - & - & - & 1 \\
\hline Human healthy baby & O81:H- & 1 & - & - & + & - & - & - & - & - & - & - & - & 1 \\
\hline Human healthy baby & $\mathrm{O} 154: \mathrm{H}-$ & 1 & + & - & - & - & - & - & - & - & - & - & - & 1 \\
\hline Human healthy adult & Ont: H18 & 1 & + & + & - & + & + & + & - & - & - & - & - & 5 \\
\hline Human healthy adult & O75 : H7 & 1 & + & - & - & - & + & - & - & - & - & - & + & 3 \\
\hline Human healthy adult & O6:H1 & 1 & - & - & - & - & + & - & - & - & - & - & + & 2 \\
\hline Human healthy adult & O16:H6 & 1 & - & - & - & - & + & - & - & - & - & - & - & 1 \\
\hline Human healthy adult & $\mathrm{O} 120: \mathrm{H} 4$ & 1 & - & - & - & - & - & + & - & - & - & - & - & 1 \\
\hline
\end{tabular}


animal isolates. This trend was even more striking among the infant isolates, where $22 / 29(75.9 \%)$ were resistant to ampicillin.

The high prevalence of antibiotic resistance among the strains isolated from healthy babies under 1 year of age, 24/ $87(28 \%)$, who had not had contact with antibiotics for at least 2 weeks prior to the specimen being taken, may be considered surprising (Bettelheim et al., 1974a). It is suggested that such resistant $E$. coli originated from the mother's faecal flora or from the hospital environment and nursing staff (Bettelheim et al., 1974b) at the time the baby was born, although it is possible that resistant strains persisted longer than 2 weeks in babies that may have been treated with antibiotics. Alternatively, these babies may have become colonized from food containing antibiotic-resistant organisms or from the environment. Studies on the acquisition of E. coli by neonates carried out in the United Kingdom (Bettelheim et al., 1974a, b, c), where antibiotic resistance was used as an additional phylogenetic marker, demonstrated that $33 / 102(32.4 \%)$ isolates were resistant to at least one of the antibiotics tested. This pattern of antibiotic resistance observed in the neonates was similar to the pattern of resistance in isolates recovered from the mothers. This suggests that infants may acquire antibiotic-resistant $E$. coli from their mothers, which then remain a part of their microbial flora for considerable periods after birth. The percentage $(32.4 \%)$ of resistance found then is within the same order of magnitude as that found in the current study $(28 \%)$ and suggests that a quarter to a third of E. coli resident in the human intestinal tract at any one time may carry antibiotic resistance characteristics. Consistent with these observations, a recent study of the presence of integronassociated resistance in Enterobacteriaceae recovered from patients recently admitted to hospital showed that $19 \%$ carried integrons (Leverstein-van Hall et al., 2002). These authors concluded that integrons, most probably acquired from bacteria linked to the food chain, are widespread in the community. A similar Australian study reported that 59/120 human urinary isolates belonging to the Enterobacteriaceae, of which 90 were E. coli, possessed integrons containing cassettes that confer resistance to trimethoprim and aminoglycosides (White et al., 2001). Studies by Lidin-Janson et al. (1977) reported that 102/709 (14.4\%) E. coli recovered from 771 rectal swabs from healthy school children were resistant to antibiotics and these authors concluded that the resistant strains were likely to be animal-derived strains. These studies highlight the need to determine baseline prevalence rates of antibiotic-resistant bacteria and the genes responsible for conferring resistance among healthy adult humans.

These studies strongly suggest that the development of antibiotic-resistant E. coli, either VTEC or non-VTEC, should not be a major concern under the current Australian animal husbandry regime for cattle and sheep. However, more extensive studies are required to establish the levels of antibiotic resistance among populations of bacteria from meat-producing animals across a range of production systems. The identification of resistant VTEC belonging to serotypes $(\mathrm{O} 5: \mathrm{H}$ - and $\mathrm{O} 111: \mathrm{H} 8)$ which are uncommonly found in healthy Australian cattle, and which are accepted human pathogens (Starr et al., 1998; Paton et al., 1996) and may also be animal pathogens (Hornitzky et al., 2000) in Australia, suggests that the use of antibiotics to treat sick animals may play a role in the emergence of antibioticresistant VTEC. Generally, most of the resistant serotypes isolated from the healthy babies belonged to types commonly isolated from healthy humans, such as those belonging to Ogroups O1, O2, O4, O6, O7, O25 and O75 (Bettelheim, 1997) and not to typical bovine or ovine serotypes.

\section{ACKNOWLEDGEMENTS}

We wish to acknowledge with thanks the excellent technical assistance of Ms Irene Petalotis.

\section{REFERENCES}

Acheson, D. W. K., Keusch, G. T., Lightowlers, M. \& Donohue-Rolfe, A. (1990). Enzyme-linked immunosorbent assay for Shiga toxin and Shiga-like toxin II using $\mathrm{P}_{1}$ glycoprotein from hydatid cysts. J Infect Dis 127, 1145-1150.

Bettelheim, K. A. (1997). Escherichia coli in the normal flora of humans and animals. In Escherichia coli Mechanisms of Virulence, pp. 85-109. Edited by M. Sussman. Cambridge: Cambridge University Press.

Bettelheim, K. A. (2001). Enterohaemorrhagic Escherichia coli O157: H7: a red herring? J Med Microbiol 50, 201-202.

Bettelheim, K. A. \& Thompson, C. J. (1987). New method of serotyping Escherichia coli: implementation and verification. J Clin Microbiol 25, 781-786.

Bettelheim, K. A., Breadon, A., Faiers, M., O'Farrell, S. M. \& Shooter, R. A. (1974a). The origin of 'O' serotypes of Escherichia coli in babies after normal delivery. J Hyg 72, 67-70.

Bettelheim, K. A., Teoh-Chan, C. H., Chandler, M. E., O'Farrell, S. M., Rahamim, L., Shaw, E. J. \& Shooter, R. A. (1974b). Further studies of Escherichia coli in babies after normal delivery. J Hyg 73, 277-285.

Bettelheim, K. A., Teoh-Chan, C. H., Chandler, M. E., O'Farrell, S. M., Rahamim, L., Shaw, E. J. \& Shooter, R. A. (1974c). Spread of Escherichia coli colonizing new-born babies and their mothers. J Hyg 73, 383-387.

Beutin, L., Geier, D., Steinrück, H., Zimmermann, S. \& Scheutz, F. (1993). Prevalence and some properies of verotoxin (Shiga-like toxin)producing Escherichia coli in seven different species of healthy domestic animals. J Clin Microbiol 31, 2483-2488.

Chandler, M. E. \& Bettelheim, K. A. (1974). A rapid method of identifying Escherichia coli ' $\mathrm{H}$ ' antigens. Zentbl Bakteriol Parasitenkd Hyg I Abt Orig A 129, 74-79.

Djordjevic, S. P., Hornitzky, M. A., Bailey, G., Gill, P., Vanselow, B., Walker, K. \& Bettelheim, K. A. (2001). Virulence properties and serotypes of Shiga toxin-producing Escherichia coli from healthy Australian slaughter-age sheep. J Clin Microbiol 39, 2017-2021.

Dorn, C. R., Scotland, S. M., Smith, H. R., Willshaw, G. A. \& Rowe, B. (1989). Properties of verocytotoxin-producing Escherichia coli of human and animal origin belonging to serogroups other than $\mathrm{O} 157: \mathrm{H} 7$. Epidemiol Infect 103, 83-95.

Fagan, P. K., Hornitzky, M. A., Bettelheim, K. A. \& Djordjevic, S. P. (1999). Detection of Shiga-like toxin (stx1 and stx2), intimin (eaeA), and enterohemorrhagic Escherichia coli (EHEC) hemolysin (EHEC hlyA) genes in animal feces by multiplex PCR. Appl Environ Microbiol 65, 868-872.

Garrett, L. (1995). The Coming Plague. London: Virago Press. 
Glynn, M. K., Bopp, C. \& Dewitt, W. (1998). Emergence of multidrugresistant Salmonella enterica serotype typhimurium DT104 infection in the United States. N Engl J Med 338, 1333-1338.

Gonzales, E. A. \& Blanco, J. (1989). Serotypes and antibiotic resistance of verocytotoxigenic (VTEC) and necrotizing (NTEC) Escherichia coli strains isolated from calves with diarrhoea. FEMS Microbiol Lett 51, 31-36.

Hornitzky, M. A., Bettelheim, K. A. \& Djordjevic, S. P. (2000). The isolation of enterohaemorrhagic Escherichia coli O111: H- from Australian cattle. Aust Vet J 78, 636-637.

Hornitzky, M. A., Bettelheim, K. A. \& Djordjevic, S. P. (2001). The detection of Shiga toxin-producing Escherichia coli in diagnostic bovine faecal samples using vancomycin-cefixime-cefsulodin blood agar and PCR. FEMS Microbiol Lett 198, 17-22.

Johnston, R. E. (1987). In Pig Production Vol. II (Proceeding Number 95), J. D. Stewart Memorial Refresher Course for Veterinarians, pp. 779788. Sydney, Australia: University of Sydney.

Khan, A., Das, S. C., Ramamurthy, T., Sikdar, A., Khanam, J., Yamasaki, S., Takeda, Y. \& Balakrish Nair, G. (2002). Antibiotic resistance, virulence gene, and molecular profiles of Shiga toxin-producing Escherichia coli isolates from diverse sources in Calcutta, India. J Clin Microbiol 40, 2009-2015.

Konowalchuk, J., Speirs, J. L. \& Stavric, S. (1977). Vero response to a cytotoxin of Escherichia coli. Infect Immun 18, 775-779.

Kudva, I. T., Hatfield, P. G. \& Hovde, C. J. (1997). Characterization of Escherichia coli O157:H7 and other Shiga toxin-producing E. coli serotypes isolated from sheep. J Clin Microbiol 35, 892-899.

Leung, P. H. M., Yam, W. C., Ng, W. W. S. \& Peiris, J. S. M. (2001). The prevalence and characterization of verotoxin-producing Escherichia coli isolated from cattle and pigs in an abattoir in Hong Kong. Epidemiol Infect 126, 173-179.

Leverstein-van Hall, M. A., Paauw, A., Box, A. T. A., Blok, H. E. M., Verhoef, J. \& Fluit, A. C. (2002). Presence of integron-associated resistance in the community is widespread and contributes to multidrug resistance in the hospital. J Clin Microbiol 40, 3038-3040.

Levy, S. \& Cruz, J. (1999). Two Americas confront antibiotic resistance. ASM News 65, 132-133.

Lidin-Janson, G., Falsen, E., Jodal, U., Kaijser, B. \& Lincoln, K. (1977). Characteristics of antibiotic resistant Escherichia coli in the rectum of healthy school children. J Med Microbiol 10, 299-308.

Paton, A. W., Ratcliff, R. M., Doyle, R. M., Seymour-Murray, J., Davos, D., Lanser, J. A. \& Paton, J. C. (1996). Molecular microbiological investigation of an outbreak of hemolytic-uremic syndrome caused by dry fermented sausage contaminated with Shiga-like toxin-producing Escherichia coli. J Clin Microbiol 34, 1622-1627.

Ramachandran, V., Hornitzky, M. A., Bettelheim, K. A., Walker, M. J. \& Djordjevic, S. P. (2001). The common ovine shiga toxin 2-containing Escherichia coli serotypes and human isolates of the same serotypes possess a Stx2d toxin type. J Clin Microbiol 39, 1932-1937.
Richter, H., Klie, H., Timm, M., Gallien, P., Steinruck, H., Perlberg, K. W. \& Protz, D. (1997). Verotoxin-producing E. coli (VTEC) in faeces from cattle slaughtered in Germany. Berl Muench Tieraerztl Wochenschr 110 , 121-127.

Schroeder, C. M., Zhao, C., DebRoy, C., Torcolini, J., Zhao, S., White, D. G., Wagner, D. D., McDermott, P. F., Walker, R. D. \& Meng, J. (2002). Antimicrobial resistance of Escherichia coli O157 isolated from humans, cattle, swine, and food. Appl Environ Microbiol 68, 576-581.

Sotto, A., de Boever, C. M., Fabbro-Peray, P. Gouby, A., Sirot, D. \& Jourdan, J. (2001). Risk factors for antibiotic-resistant Escherichia coli isolated from hospitalized patients with urinary tract infections: a prospective study. J Clin Microbiol 39, 438-444.

Starr, M., Bennett-Wood, V., Bigham, A. K., de Koning-Ward, T. F., Bordun, A. M., Lightfoot, D., Bettelheim, K. A., Jones, C. L. \& RobinsBrowne, R. M. (1998). Hemolytic-uremic syndrome following urinary tract infection with enterohemorrhagic Escherichia coli: case report and review. Clin Infect Dis 27, 310-315.

Stephan, R. \& Kuhn, K. (1999). Prevalence of verotoxin-producing Escherichia coli (VTEC) in bovine coli mastitis and their antibiotic resistance. J Vet Med 46, 423-427.

Threlfall, E. J., Ward, L. R. \& Rowe, B. (1997). Increasing incidence of resistance to trimethoprim and ciprofloxacin in epidemic Salmonella typhimurium DT104 in England and Wales. Eurosurveillance 2, 81-84.

Wells, J. G., Shipman, L. D., Green, K. D. \& other authors (1991). Isolation of Escherichia coli O157:H7 and other Shiga-like toxinproducing E. coli from dairy cattle. J Clin Microbiol 29, 985-989.

White, P. A., Mclver, C. J. \& Rawlinson W. D. (2001). Integrons and gene cassettes in the Enterobacteriaceae. Antimicrob Agents Chemother 45, 2658-2661.

Wieler, L. H., Vieler, E., Erpenstein, C., Schlapp, T., Steinruck, H., Bauerfeind, R., Byomi, A. \& Baljer, G. (1996). Shiga toxin-producing Escherichia coli strains from bovines: association of adhesion with carriage of eae and other genes. J Clin Microbiol 34, 2980-2984.

Willis, C. (2000). Antibiotics in the food chain: their impact on the consumer. Rev Med Microbiol 11, 153-160.

Willshaw, G. A., Cheasty, T., Smith, H. R., O’Brien, S. J. \& Adak, G. K. (2001). Verocytotoxin-producing Escherichia coli (VTEC) O157 and other VTEC from human infections in England and Wales: 1995-1998. J Med Microbiol 50, 135-142.

Wong, C. S., Jelacic, S., Habeeb, R. L., Watkins, S. L. \& Tarr, P. I. (2000). The risk of the hemolytic-uremic syndrome after antibiotic treatment of Escherichia coli O157: H7 infections. N Engl J Med 342, 1930-1936.

Zhao, S., White, D. G., Ge, B., Ayers, S., Friedman, S., English, L., Wagner, D., Gaines, S. \& Meng, J. (2001). Identification and characterization of integron-mediated antibiotic resistance among shiga toxinproducing Escherichia coli isolates. Appl Environ Microbiol 67, 15581564.

Zimmerhackl, L. B. (2000). E. coli, antibiotics, and the hemolyticuremic syndrome. N Engl J Med 342, 1990-1991. 